\title{
A Strategic Planning for a College Student-Segment Shopping Mall
}

\author{
Astri Anindya Sari*, Hanson Endra Kusuma**, Baskoro Tedjo*** \\ SAPPK, Institut Teknologi Bandung - Indonesia
}

\begin{tabular}{l} 
A R T I C L E I N F O \\
Received: February 20, 2011 \\
Final revision: July 10, 2011 \\
\hline Keywords: \\
shopping mall, \\
students, preferences, \\
spatial physical characteristics, \\
activity.
\end{tabular}
activity.

\section{A B S T R A C T}

In the midst of shopping mall development today, an understanding of consumer behaviors and preferences is absolutely a must if we want to plan successfuly a shopping mall. This knowledge will provide input for strategic planning so that the concept offered for shopping mall development will meet the consumers' demand and may win the market competition. This study explores the preferences of students in Bandung as one of the potential market segments of the shopping mall. Qualitative study was conducted to find out the reasons why students choose a particular shopping mall as their favorite place. It was found that the accessibility and design of the malls are important as they enhance student preferences. In addition facilities in a shopping mall which mainly attract college students segment are entertainment facilities and eating counters.
$\mathrm{A}$ lthough shopping mall culture was first known in the western countries, the current era of globalization has increasingly promoted the global widespread development of shopping malls including in major cities in Indonesia. The rapid development of shopping malls influences the lifestyle of urban community (Erkip, 2002). As the economy improves, shopping malls are no longer only seen as a place to go shopping for the daily needs but they have become an attractive place for recreation and socializing.
The change in lifestyle is perceived as a business opportunity for developers in the retail and commerce sector which immediately turns into a competition to develop shopping malls with each of their unique concepts and appealing features. An understanding of consumer behaviors is essential to determine the appropriate concept of a mall targeted to specific segments of consumers. Through an understanding of consumer behaviors, a concept that is designed will suit the consumers' tastes, desires and needs, leading the mall to achieve the objective of earning profits. 


\section{Consumer Behaviors in Malls}

One research approach that is often applied to understand consumer behaviors in a shopping mall is consumer decision making style. This approach maps the kinds of visitors to shopping malls and their behaviors so that it is easier to define the right concept to attract visitors of a particular category. Patel (2008) in his research in India divides the types of shopping mall visitors into 6 categories: price consciousness, quality consciousness, confused by over choice, novelty conscious, variety seeking and recreational. Of the six categories, the first five are mall visitors with utilitarian motivation, that is when their behaviors and ultimate goal in going to a shopping mall is to purchase goods (productoriented). Meanwhile, visitors classified in the las category or the recreational one have hedonic motivation, in that they enjoy activities in the mal for their entertainment or recreational facilities.

University students are consumers of shopping malls within the age range of 18-25. This age range is based on the physiological and psychologica development which can be categorized into the transitional phase from late adolescence to young adulthood. However, according to Hurlock (1996) the education of these students (aged above 18 years) makes them still surrounded by their peers. Therefore, they are seen to reflect the traits of behaviors of adolescents. The prominen characteristic of this phase is a social behavior tha values the importance of relationships with peer or friends in shared activities. A group of friends or an activity generally influences the behavior and values of the individual members.

Adolescents, especially female, are considered one of the potential market segments for the shopping mall (Barker \& Haytko, 2000). However, there have been only few studies conducted on adolescen behaviors towards the shopping mall as studies tend to be more focused on adult consumers. The studies on adolescent behaviors towards the shopping mal have been carried out in the UK (Matthews et al. 2000), USA (Barker \& Haytko, 2000), Turkey (Tabak et al., 2006) and Jakarta-Indonesia (Wagner, 2009). These four studies show consistent results that most adolescents use the mall as a place for and socializing with friends. A mall is considered an interesting place because there they can see and do things in their free time (Matthews et al., 2000). Furthermore, Wagner (2009) based on the results of his study in Jakarta-Indonesia divides adolescent visitors into two categories: real shopper-beginner shopper and socialize shopper. A real shopper beginner shopper tends to enjoy window shopping and perceives shopping in the mall as a form of entertainment, while a socialize shopper tends to see going to the mall as a way of having fun and socializing with friends. The fundamental difference of the two groups is the preference of the facility they enjoy, but the main motivation tends to be similar, that is for recreation and having fun (hedonic motivation). The results of these studies are also corroborated by the studies results by Patel (2008) in India, Erkip (2002) in Turkey, and Massicote et al. (2011) in Mexico which show that the respondents in the category of recreational shopping (hedonic motivation) tend to be in the age range of adolescents to young adults which is 11-20 years of age.

Factors that influence shopping experience in the mall as proposed by Abraham \& Wee (2002) include aspects of transport, retail and personal. Aspects of transport include location, which is related to accessibility, and the distance and travel time to the shopping mall. Aspects of retail include the availability and a wide range of retail products, promotions and discounts, the ambiance, and the complete facilities such as cafés, food outlets and entertainment facilities. The aspect of personal is consumer motivation in visiting the shopping mall, which affects the preference for the desired quality of the shopping mall (aspects of location and retail) in the process of making the decision on which mall to visit. Visitors with utilitarian motivation are likely to have different preferences from those with hedonic motivation (Abraham \& Wee, 2002).
Visitors with hedonic motivation go to the mall not only for shopping but also for other purposes such as to get enterti activities, to socialize, or just to do window shopping (Erkip, 2002; Sit \& Merrilees, 2005; Ooi \& Loo, 2006; Sit \& Marrilees, 2005; Massicotte et al., 2011). In choosing which mall to visit, they consider more factors, especially the retail aspect (functional) which includes the entertainment facilities provided and the retail aspect (affective) which includes the convenience and ambiance created by the design of the shopping mall ( Ibrahim \& Wee, 2002; Sit \& Merrilees, 2005). The two aspects, according to Sit \& Merrilees (2005), are important determinants of the satisfaction of this type of visitors. In the long run, visitor satisfaction will have an impact on their behavioral loyalty to the shopping mall they prefer (Sit \& Merrilees, 2005). This behavioral loyalty can be seen in their repeated visits and longer visits to a particular mall and their recommending it to those who are close to them. In planning a shopping mall, the customers' behavioral loyalty is without a doubt what a business desires to achieve. Hence, a special attention needs to be paid to the functional and affective retail aspects for a successful planning of a shopping mall that targets teens (hedonic motivation).

As mentioned earlier, Wagner (2009) divides adolescent consumers in the mall into the categories of a real shopper-beginner shopper and a socialize shopper. The former enjoys shopping activity in the mall as a form of entertainment, which means that for their satisfaction the availability of the desired goods, the range of options, the quality of goods, and the price are specific elements that must be considered. The ambiance of the mall created by its physical design is a factor which supports the convenience in shopping, so it should also receive a special attention. On the other hand, the latter tends to enjoy the mall as a place for socializing, therefore, providing a different experience. Visitors of this type tend not only to shop but they also enjoy the entertainment facilities. For their satisfaction, they would assess the shopping mall whether it provides entertainment facilities such as cinemas and eateries, as well as the cozy and pleasant ambiance created by its design. According to Tabak et al., (2006) facilities frequently visited by adolescents are cinemas, cafés, clothing store (boutiques), and other entertainment facilities. This finding confirms the findings by Ooi \& Loo (2006) in Singapore which show that one of the bigges appeals of the shopping malls is the entertainment facilities, especially cinema.

The influence of gender on the preference for facilities in the shopping mall is suggested by Wagner (2009) in research on adolescent behaviors in three shopping malls in Jakarta, Indonesia. According to Wagner (2009) female adolescents tend to be in the category of a real shopper beginner shopper who prefers shopping only, while male adolescents tend to be classified as a socialize shopper who prefers entertainment and socializing in the mall. The needs of both groups need to be addressed in the planning of a shopping mall tha targets both male and female adolescents.

Factors the consumers consider in selecting shopping mall to visit have been researched in some previous studies but they are still limited to the general aspects (functional) and have yet to include aspects of physical quality of a shopping mall. A shopping mall with a good quality design which fits the preference of consumers will provide a pleasant spatial ambiance and experience for visitors, and it will ultimately influence customer satisfaction with the mall. This study aims to explore the appeals of shopping malls to students in Bandung, Indonesia with the emphasis on the functional aspects and the quality of the physical spatial of the space. Thus, the results of this study will be useful as a reference fo strategic development of shopping malls that targe youth segment in Indonesia, especially in Bandung.

Preference for Spatial Physical Characteristics of Environment

Jahn Gehl (1986) argues that basically there are three categories of activities in public space. They 
are functional activities (necessary activities) which are planned to be carried out in that place, secondary activities (optional activities), and social activities (Gehl, 1986). Places with poor quality public space only accommodate functional activities, with some possible secondary activities. Meanwhile, public places that are well designed or have high quality public space can encourage people to stay longer and become regular visitors, so secondary activities and socializing are more likely to take place.

In the case of malls, a poorly designed mall will only accommodate shopping as a functional activity. Visitors with hedonic motivation, especially teenagers who go to the mall for fun and socializing with friends, need more than just shopping. Therefore, the planning of functions and design of a mall plays an important role in creating a visiting experience which accommodates the activities and interests of visitors with hedonic motivation.

A number of studies to determine the preference for quality of the visual, physical and spatia environment have been carried out by Berlyne $(1960,1974)$, Whyte (1980), and Nasar (1998). Berlyne $(1960,1974)$ conducted a study to determine the factors that influence the preference for the environmental aesthetic quality (Bell et al., 1996). These factors include the elements that make up the environment (complexity), the element of novelty and the elements of surprisingness. In cities, environmental factors that affect the preferences as described by Nasar (1997) are naturalness, upkeep/ civilities, openness in terms of space, historical civilities, and order. Meanwhile, Whyte (1980) adds places to sit and food vendors as two factors that lead to an open space to be preferred.

Concerning shopping malls, Barker \& Haytko (2000) conducted a study to determine the preference of female adolescents for the ideal physical quality of a mall. It is found that female adolescents in the United States want seats provided for them to rest in a shopping mall, so that they can spend longer time in the mall without worrying about getting tired. They also prefer a spacious shopping mall, with fairly wide pedestrian paths. In addition, the arrangement or the grouping of outlets or shops according to the targeted segments of consumers is also preferred because it will be much easier for them to find what they want

These studies have been conducted in western countries which have spatial physical qualities which are distict from those in Indonesia, so it is necessary to confirm those results with the condition in Indonesia. This study aims to map out the factors that encourage the preferences of students in Bandung for the malls. These factors are categorized into physical characteristics, spatial, activity, and emotional and cognitive responses. Thus, the study can find out which characteristics and ambiance of the mall preferred by students in Bandung.

\section{METHODS}

\section{Research Methods}

This is an exploratory study that aims to map the driving factors in students' preference for a shopping mall as their favorite place for recreational activities and spending leisure time. It used a qualitative method in the data collection and analysis, and it also used an instrument of open questions asked to the respondents as it is considered to be the most appropriate for this type of study. The use of this method provides an opportunity for the researchers to obtain a variety of possible answers from the respondents, including those that may not be previously expected. The results obtained thus will be richer when compared with those resulted from the use of quantitative method which uses an instrument with previously prepared answer choices (Creswell, 2002).

The respondents of the study were students of higher education institutions in Bandung in Tamansari Dago including Unisba, Unpas, ITB, UNIKOM, and Unpad Dipatiukur. The number of samples was determined proportionally based on the comparison of the number of students in each institution (proportional sampling). While the respondents from each campus were selected randomly (random / quota sampling), they had to meet the criterion of being undergraduate students at least in their second year. The criterion is chosen based on the consideration that these undergraduate students have similar age and psychological development and the complex needs. In addition, students in their second year or higher are assumed to have a cognitive map of the city of Bandung.

The data used in this study is part of the data of the primary research aimed at exploring student favorite places in the city. The results show that the mall ranks first as the most favorite place to visit when the students feel bored or tired of the activities in classes. Of the 303 students who participated as respondents, 112 or $37 \%$ chose a mall as their favorite. The data of the 112 students who chose the mall as their favorite place were used in this study to learn more about factors that influence them in choosing a particular mall as a favorite.

The data were collected using a questionnaire and brief interview with some open questions including: 1. Please mention your favorite place to go when you're feeling bored or tired with the classes in campus; 2. Reasons for choosing that place; 3 . The places visited in that favorite place. The personal characteristics of respondents were distinguished by their gender: male and female.

The answer to the first question is presented by the frequency distribution to determine different malls most favored by students. Questions 2 and 3 which are about the reasons for the selection of the favorite place and places visited while in the chosen favorite place were analyzed qualitatively and by content analysis. Content analysis was conducted by grouping keywords from the responses of the respondents which were quite similar in meaning and categorizing them based on the variables of physical characteristics, spatial, activity, an emotional and cognitive responses. The results of content analysis provide information about the

\begin{tabular}{|c|c|c|}
\hline Index & Topic & Summary \\
\hline 1 & Strategy Alignment & $\begin{array}{l}\text { - Strategy is easily aligned to all personnel due to the small number of size } \\
\text { - "Differentiation" Strategic Positioning } \\
\text { - "Survive" strategy on project-based development } \\
\text { - User experience design as the company's distinctive competencies }\end{array}$ \\
\hline 2 & $\begin{array}{l}\text { The level of the } \\
\text { importance of the } \\
\text { main issue }\end{array}$ & $\begin{array}{l}\text { - Becomes an emerging issue, especially due to anticipate the changing } \\
\text { business focus and for long-term purpose } \\
\text { - More focus on Structure, although still facilitate the Creativity side on } \\
\text { current project-based business. The portion could be changed due to the } \\
\text { business shifting }\end{array}$ \\
\hline 3 & Practice of Creativity & $\begin{array}{l}\text { • "Innovation Day" } \\
\text { •Blogging" }\end{array}$ \\
\hline 4 & Structure Applied & $\begin{array}{l}\text { - Business Process } \\
\text { - Organizational Structure } \\
\text { - Policy }\end{array}$ \\
\hline 5 & $\begin{array}{l}\text { Relationship } \\
\text { between Creativity } \\
\text { and Structure }\end{array}$ & $\begin{array}{l}\text { - There is relationship between them, especially related to project delivery } \\
\text { and competency } \\
\text { - More portion on Structure, rather than Creativity in the project-based } \\
\text { business } \\
\text { - Different opinions on the balance condition, including if compared to } \\
\text { since its establishment, or } 6 \text { months ago }\end{array}$ \\
\hline
\end{tabular}




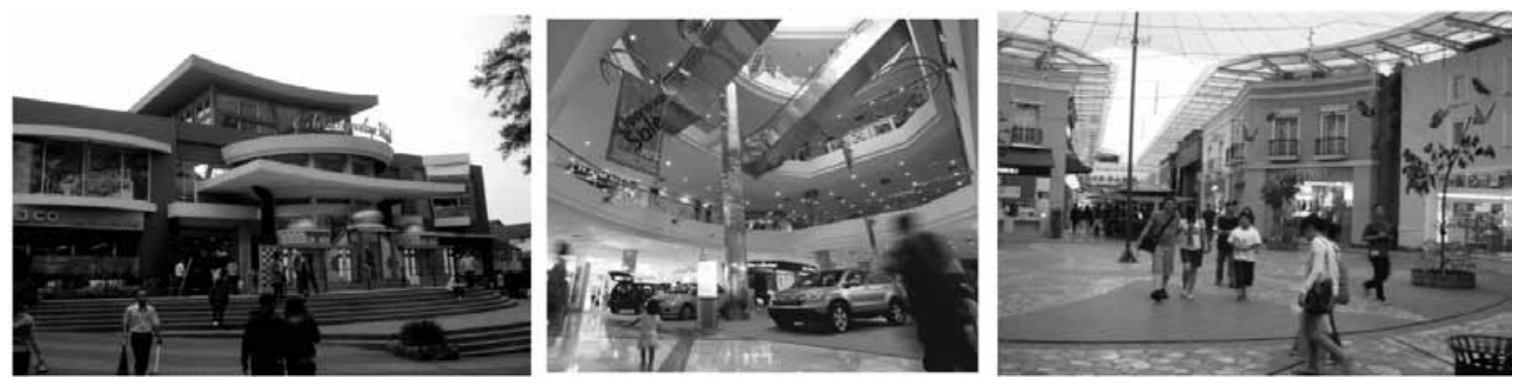

Figure 1 Ciwalk, BIP, and PVJ - three most favorite malls

physical spatial quality of the shopping mall that respondents consider in choosing a favorite mall and the activities they often do there.

\section{RESULTS AND DISCUSSION}

Favorite Malls and Driving Factors for Preferences As previously described, this study used the data from 112 respondents who chose a mall as a favorite place in the primary study. Of the 112 respondents, 74 were female, and 38 were male. From the first question in the questionnaire that asks the respondents to name a favorite place to visit when they feel bored or tired with the classes, we can see that mapping of the most preferred malls by respondents in figure 1 . Those malls are Ciwalk (34\%), BIP (30\%), PVJ (20\%), followed by BEC (6\%) and Dago Plaza (4\%) while other malls (King's, Braga City Walk, BTC, and IP) are only minority. The high preference of respondents for Ciwalk, BIP, and PVJ demonstrates the success of their management strategies in attracting attracting students as consumers.

The driving factors for the preference of the respondents for a particular mall as their favorite are presented in diagram 1 . The factors mentioned by the respondents are categorized into variables of physical characteristics, facilities, spatial, activity, and the cognitive and emotional responses the respondents felt while in their favorite mall. The results of the analysis reveal the characteristics of the mall preferred by students, and activities and ambiance expected to be found in their favorite mall.
The categorization of driving factors for preference for a shopping mall is consistent with the categorization conducted by Abraham \& Wee (2002). According to Abraham \& Wee (2002), factors that affect shopping experience is the transport aspect, retail aspect, and personal aspect. In this study, the transport aspect is mentioned as a spatial characteristic that is related with the accessibility to and from the favorite mall. Meanwhile, the retail aspect discussed in this study puts more emphasis on the quality of the physical and functional space of the shopping mall.

The knowledge of physical characteristics will give inputs on aspects that must be designed by the architect in the shopping mall. Meanwhile, the aspects of facilities and activities will provide inputs into the spatial program planning which needs to be accommodated by the shopping mall to make it favored by students.

Diagram 1 shows that in terms of physical aspect the design of the mall is the main element that encourages respondents to choose a particular mall as their favorite. Meanwhile, from the aspect of facilities, it is found that a variety of places and activities to do in the mall is the dominant element that affects the preference for a shopping mall. It means that a mall is favored because it offers a variety of places to visit and a variety of activities, which better provide an enjoyable experience for shopping mall is also preferred because it offers a range of options of eateries. Easy accessibility visitors with hedonic motivation. In addition, a

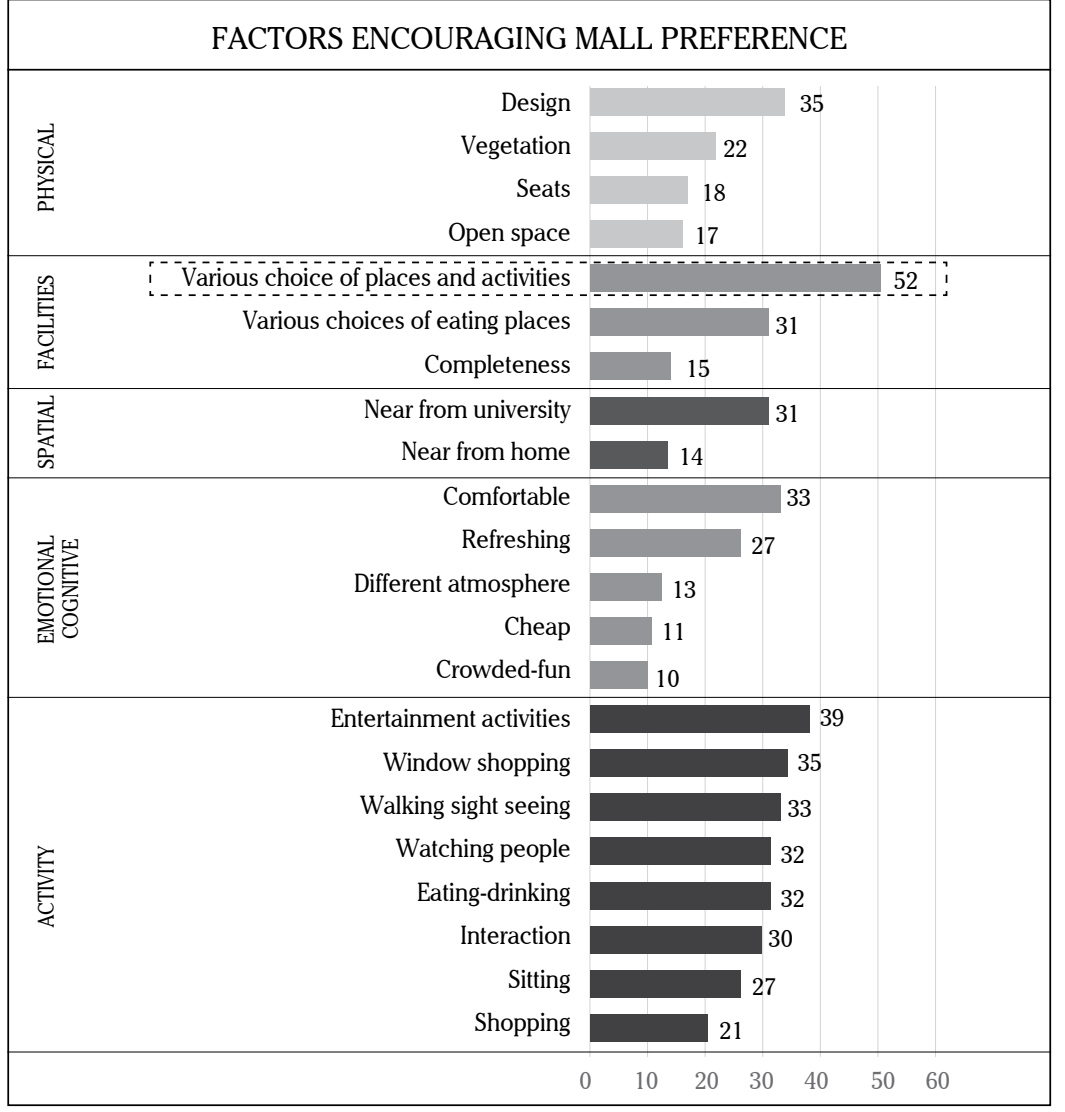

Diagram 1. Driving factors for preference for a mall

especially from the campus is the dominant spatial element which affects the preference for a particular mall. The physical quality and the facilties in the mall make the respondents feel comfortable and provide an ambiance which is different from their daily life, making them enjoy the restorative (refreshing) process in the shopping mall.

The activities mostly done in the mall are entertainment, having meals, going for a walk, and active interaction activities (with friends), and passive interaction (window shopping, watching people, hanging out). Other activities which are done but with lower frequency are to sit around and to go shopping. We can see that shopping which should be the main activity in the mall occupies the lowest position in the frequency distribution, while the entertainment-related activities are most frequently done. These results show that similar to teenagers in the UK, USA, Turkey and India (Matthews et al., 2000; Barker \& Haytko, 2000; Tabak et al., 2006; Patel, 2008), students in the location of this study go to the mall with hedonic motivation. Therefore, the physical elements that include the design and facilities of the mall need to be given a special attention in order to create an ambiance which can provide enjoyable recreation experience sought by this group.

Preferred Spatial Physical Elements in the Mall

It has been mentioned earlier that Ciwalk, BIP, and PVJ are the most preferred shopping malls by students in this study. To determine the attractive qualities of the three malls from the perspective of their physical and spatial aspects, the spatial physical elements of Ciwalk, BIP, and PVJ are compared and they are shown in diagram $2 \& 3$.

Diagram 2 on the the spatial elements which drive their preference for the mall shows that the element of location, especially the proximity to campus plays an important role. Location is closely related to easy access, travel time and costs spent to get to the mall. The closer the location of the mall from the 


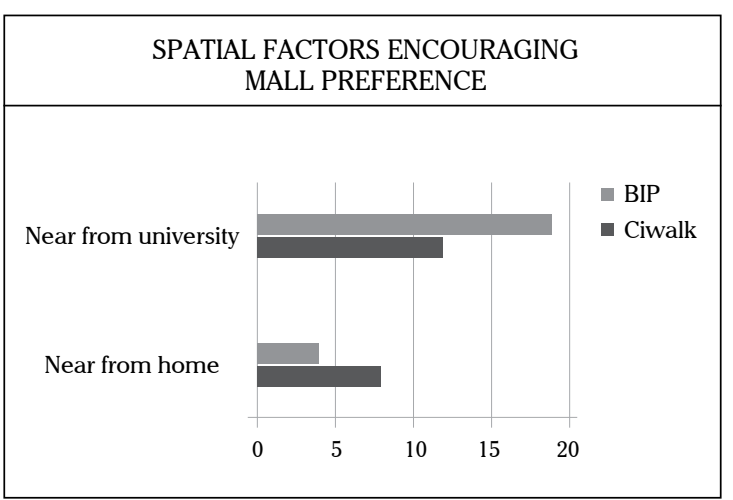

Diagram 2. Spatial elements encouraging the preference for a mall

campus, the greater the chance that it is preferred by students. As shown by Diagram 2 above, the two most favorite malls (Ciwalk and BIP) have the advantage as their location is close to the campus. Meanwhile, PVJ which is not located near a campus or a residential area only comes third.

In addition to the location, another element to consider in the planning of a mall to make it appealing especially among students is the physical elements that include the design, vegetation, seats, open space, and a variety of eateries available. Diagram 2 shows that Ciwalk, or the most favorite mall, include all these elements in its physical planning. Whereas, PVJ which is already less fortunate in terms of location managed to rank as the third favorite because it has a good and appealing design. The element of design also becomes the advantage of PVJ when compared with other malls which are only elected by a minority of respondents. These malls are neither close to the campus location nor supported by an attractive design.

The importance of elements of location and design in influencing students' preference for a particular mall as can be seen from some of the following reasons which are cited from the respondent's answer:

A respondent who chose Ciwalk:

"Because the location of Ciwalk is close to the

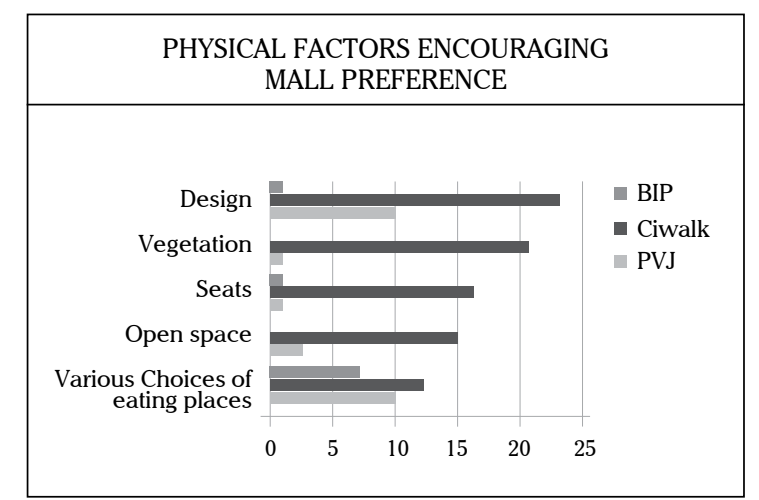

Diagram 3. Spatial elements encouraging the preference for a mall

rented rooms and campus; Ciwalk is convient not only in terms of a wide range of goods but also from the beautiful Ciwalk architecture (there are gardens which can be enjoyed while in Ciwalk)."

A respondent who chose BIP:

"It is because it is close to campus, within a walking distance. If not in a good mood, I can go to BIP and see some stuff even I don't have any money. At least it can refresh my brain a little bit. I can also looking for stuff I'd like to buy, so I can know the price. I don't have to spend a lot of money to go to BIP."

A respondent who chose $\mathrm{PVJ}$ :

"There are a lot of places to visit. It has a nice interior. The concept of the mall makes it enjoyable to walking in it although I don't buy things. The eateries in PVJ have fancy designs. I prefer a nice ambiance of a place than the food, so I like sitting and eating in one place while thinking or doing something."

Therefore, it can be concluded that if a mall does not have the advantage of a strategic location, it should consider the design elements to create an appeal to visitors with hedonic motivation. The elements of design favored and taken into consideration by the respondents in selecting a mall are shown in diagram 4.

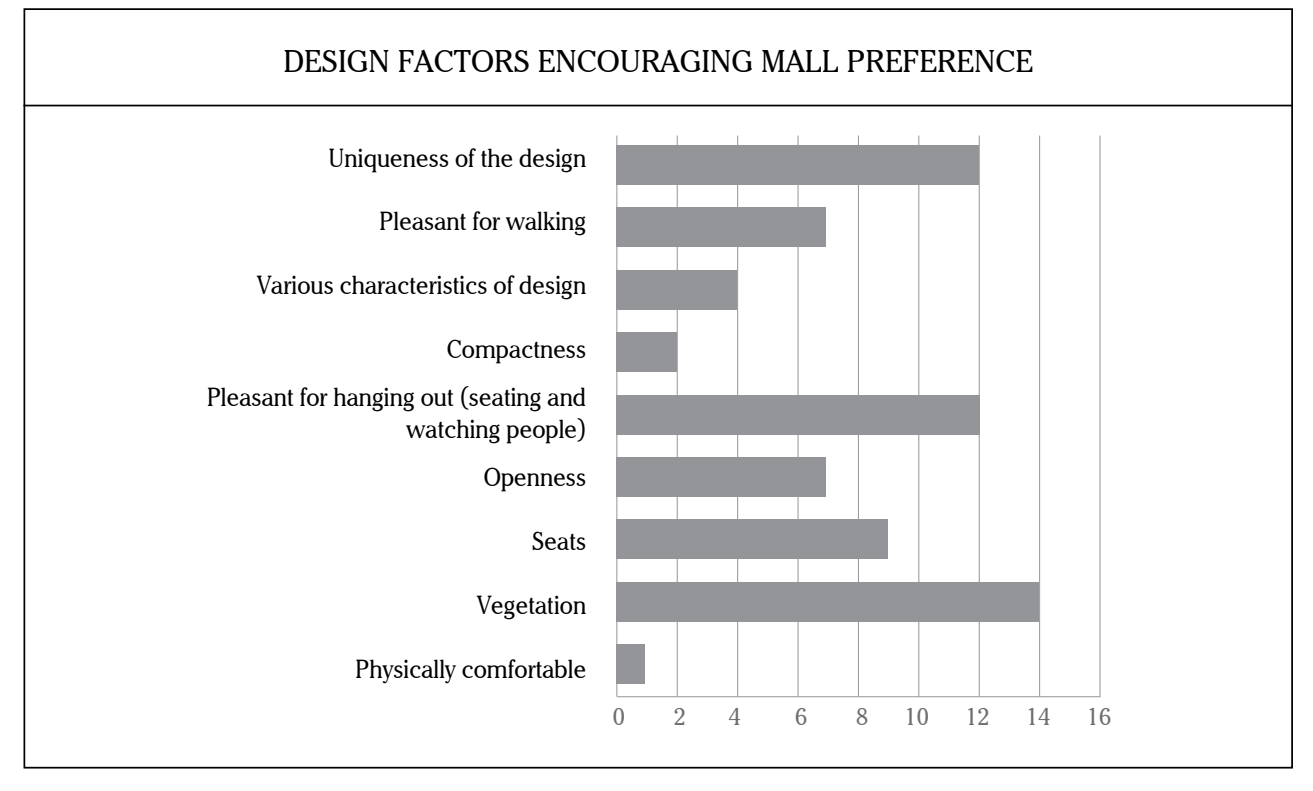
Diagram 4. Elements of design that affect preference
for a mall

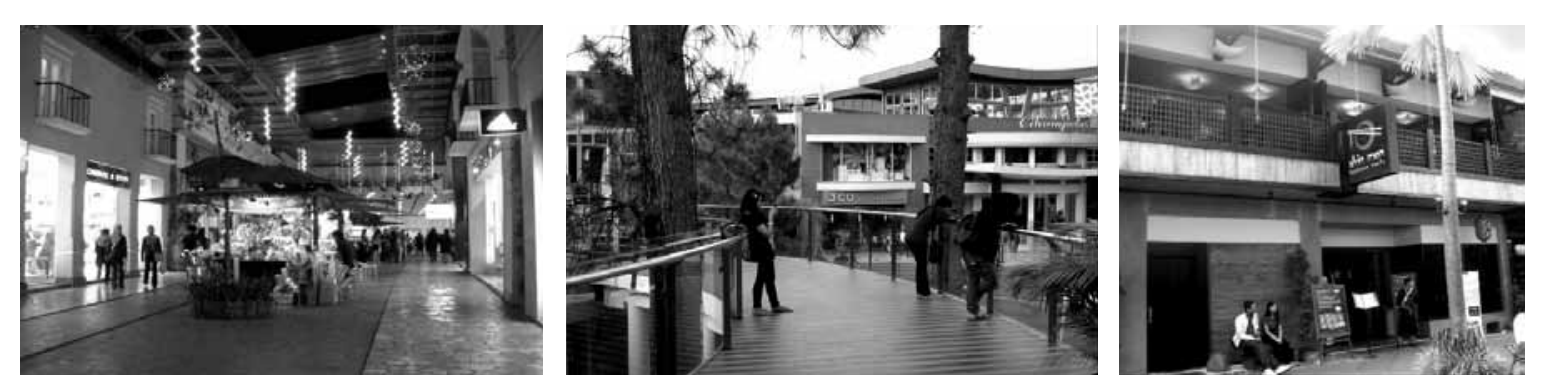

Figure 2. Mall which is 'cozy for going for a walk' - the planning of pedestrian paths which gives the pedestrians a pleasant spatial experience
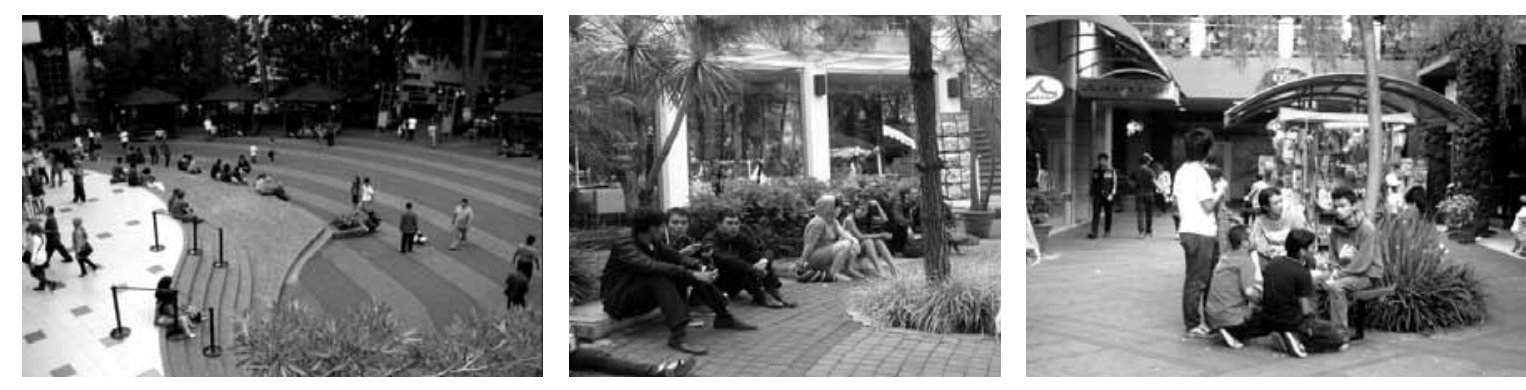

Figure 3. Mall is 'pleasant for hanging out' - the design enables the provision of seats on which people can enjoy the space freely

Of the 35 respondents who mentioned elements of design as a driving factor in choosing a particular mall as their favorite, it seems that for them the uniqueness of the design, the presence of vegetation, and designs which are suitable for hanging out are the most influential ones.
Unique, unconventional designs are special characteristics which make a shopping mal distinctive amidst the development of shopping malls in the city today. A mall with unique, unconventional designs tends to be more desirable and sought after because of its unique ambiance 
that is not easily found elsewhere. Furthermore, the openness of space, the variety of interior designs and outlets, harmonious spatial planning the provision of seats, and the vegetation element are all interrelated factors to create a good mall for going for a walk and hanging out.

The design of a mall which is "cozy for going for a walk" could be materialized when the pedestrian areas are fairly spacious and their paths are well planned. The diversity of designs of outlets along the pedestrian paths will provide a different spatial experience for visitors who walk through them and it prevents them getting bored. The harmonious spatial arrangement needs to be addressed too, to prevent the visitors from being tired.

The design is 'pleasant for hanging out' if seats are provided and there is an open space that can be used to sit and enjoy the ambiance freely. Openness regarding the space is a factor that enables visitor to see a lot of things without their view being obstructed. The element of vegetation in the mal is preferred because visitors want to feel natural ambiance while in the center of town

The results of the content analysis of the responses to the question about the places visited on a favorite place can provide some information about the mall facilities most preferred and widely used by students. The results are useful in the planning of a spatial program in a shopping mall which is intended for youth and student segments.

\section{Preferred Facilities in Shopping Malls}

Diagram 5 shows that of the 112 persons who chose a mall as their favorite place, 88 persons or $79 \%$ preferred to visit entertainment facilities, including cinema, karaoke, games and clubbing places. $70 \%$ of 112 persons visited the food court or another eatery, while a place for shopping which is supposed to be the main attraction in a shopping mall was only visited by $44 \%$ of 112 respondents. This condition further confirms that the students in the site of the study are visitors with hedonic motivation.
Diagram 5 also shows that the main appeal of a shopping mall for students is the entertainment facilities, especially cinema. This finding is consistent with the findings of a previous study conducted in Singapore (Ooi \& Loo, 2006). The results indicate the importance of planning entertainment facilities, especially the cinema that accommodates the needs of youth and students for entertainment.

In addition, another facility which should also receive an attention is food stalls or the food court. Various eateries with each of their unique designs in the mall would be appealing for students. Moreover, since this segment has yet to earn their own income, the type of food and affordability are also worth considering.

Places to shop that the respondents found interesting in the location of the study are clothing and accessories outlets. It may be because most (74 people) of the total 112 respondents who chose the mall are women, so they have a quite great interest in fashion and accessories outlets.

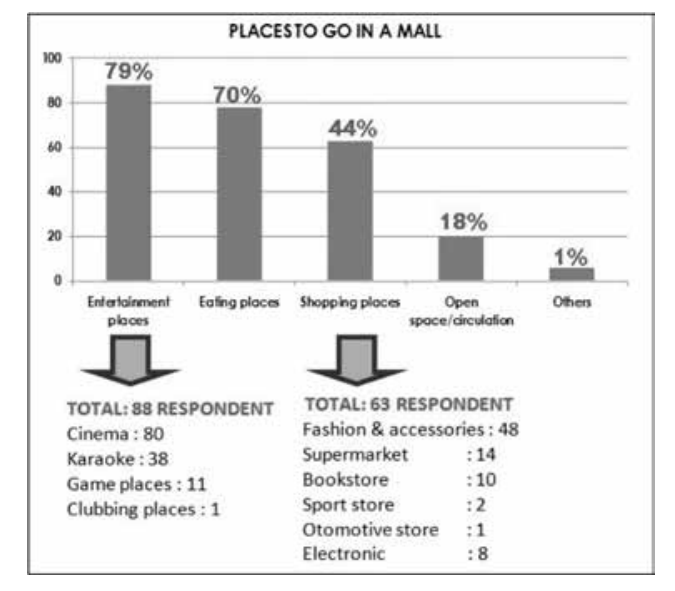

Diagram 5. Places to go in a mall, responden may choose more than one place

\section{The Influence of Gender on Mall Preference}

It has been mentioned that of 112 respondents who chose a mall as their favorite place, 74 persons were female and 38 were male. The distribution of the respondents in the most favorite malls can be seen in diagram 6 below.

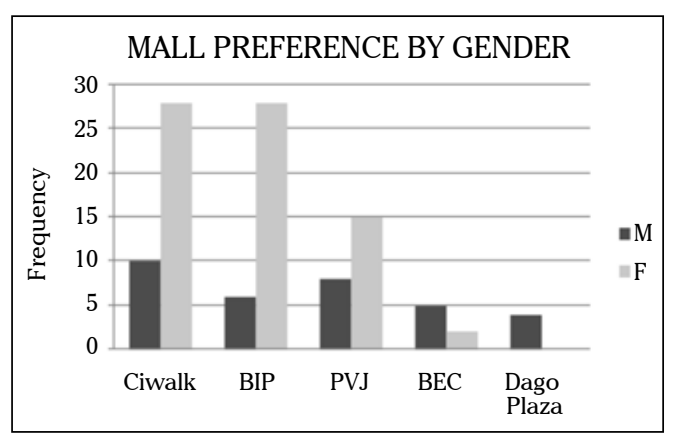

Diagram 6. Mall preference by gender

The diagram shows the three favorite malls namely Ciwalk, BIP, and PVJ and the respondents choosing them were dominated by female respondents, while the male ones preferred to visit the BEC and Dago Plaza. This may be because BEC and Dago plaza accommodate activities and products of interest of male visitors, i.e., electronics and entertainment.

From the distribution of gender in the three most favorite malls, Ciwalk, BIP and PVJ, we can see that male respondents tend to prefer Ciwalk and PVJ as they are seen to have more unique and favored designs of character over BIP with its conventional design.

Although BIP has the advantage in terms of its location and a wide range of products but without the support of unique and attractive designs, it appears less attractive among male visitors. On the other hand, BEC which specializes in electronic products attracts more male visitors than female visitors. This may be because the fact that electronic as is one of the main interests of male visitors so they feel entertained by purchasing them or just looking at the advancement of electronic products, while women tend only to come to the BEC if necessary. The two most favorite malls, Ciwalk and PVJ, have a wide range of products, the unique designs and various entertainment facilities so they attract both men and women visitors.

The results of the analysis indirectly show consistency with the results of Wagner's study
(2009) on malls in Jakarta. In a one-stop-shopping mall with its variety of products such as BIP, Ciwalk, and PVJ, female respondents tend to be a beginne shopper-real shopper while male respondents enjoy more entertainment and socializing (socialize shopper). However, this study reveals that providing special products which are of the interest of male visitors in shopping malls such as in BEC will attract more male visitors and make them a real shopper.

Hence, to attract male and female visitors, the planning should pay attention to the functional aspects of the mall by providing a wide range of products and activities which are favored by men and women. In addition, a unique design which is favored also creates an added value that supports comfortable ambiance for socializing so it can make both men and women like the mall.

\section{Conclusions and Business Implication}

An understanding of consumer behaviors and preferences will be essential to the successful planning of a shopping mall. For the segment of the teen consumers, consistent with the situation of the adolescents in the UK (Mathews et al, 2000), Turkey (Tabak et al., 2006; Erkip, 2002), USA (Barker \& Haytko, 2000), Jakarta-Indonesia (Wagner, 2009) and Mexico (Massicotte et al., 2011), the students in Bandung, Indonesia, are also likely to go to the mall with hedonic motivation as they regard malls as recreational facilities. A mall is preferred because it is seen as a place where students can see and do things that they like. Consistent results with previous studies conducted in different locations are evidence that the preference of adolescents for activities in a shopping mall is shared across cultures.

Like teenagers, students in the site of the study are also visitors with hedonic motivation. Therefore, visitors' preference for and satisfaction with a shopping mall are not only influenced by the functional aspects of retail, in this case the product sold and a wide range of facilities provided. Other factors that influence the students' preference for a shopping mall are the location and design. 
Easy accessibility from the campus is important thing to address since the function of the mall for students is as a place for socializing with friends, which is located not far from the campus. Besides the location, the design is also an important factor that makes a mall chosen as a favorite by the students. This study reveals that a special attention to the elements of design of shopping malls will compensate the weakness terms of the location. It means that a mall in a less strategic location will have a chance to be a favorite when its physical quality includes the elements of the preferred and unique design.

A favorite mall is a pleasant place for going for a walk and hanging out. Factors which make a mall to be a pleasant place are the diversity and variety of design criteria (complexity), the unconventional design (novelty), the openness of the space (openness) the elements of the nature (naturalness), as well as the available seats. The results of the study indirectly confirm studies on the preference for the environmental physical quality conducted earlier by Berlyne, Nasar, and Whyte (1980).

As a place for recreational activities, an entertainment facility especially cinema is a place mostly visited

The data used in this study were collected by the researchers and the students of Master's program in architecture, SAPPK, ITB. The researchers would like to thank Putri Herlia and Wasiska Iyati for their help during the data collection by the respondents in the mall. In addition to cinema, other places favored by the majority of respondents are eateries which are also often a place for socializing with friends. Therefore, the planning of entertainment facilities and the diversity of eateries need to be given more attention in the development of strategy for the concept of shopping malls for the segments of youth and students. The facilities especially cinema are the major attraction in the mall confirms to the studies (Barker \& Haytko, 2000; Ooi \& Loo, 2006; Tabak et al., 2006; Massicotte, 2011). Furthermore, the result which says that the presence of food vendors is a criterion that can make people get together also confirms Whyte's result (1980) on an open space.

The shopping mall has been closely associated with shopping activity which is favored by women. Therefore, the female respondents who chose a shopping mall as their favorite place tends to outnumber the male respondents. However, the planning of the activity functions (entertainment), the design of the mall and the availability of products that accommodate the interests of male consumers will be an appeal for them to visit the shopping mall. study result which states that the entertainment

Massicotte, M.C., Ryerson, R.M., Chebat, J.C \& Sirgy, M. J, (2011), Effects of Mall Atmosphere on Mall Evaluation: Teenage versus Adult Shoppers, Journal of Retailing and Consumer Services Vol 18, Issue 1, Jan 2011, pp. 74-80

REFERENCES

Baker, J. \& Haytko, D. (2000). The mall as entertainment: Exploring teen girls' total shopping experiences. Journal of Shopping Center Research, 7(1), 29-58.

Bell, P., Greene, T.C., Fisher, J.D., Baum, A. (1996), Environmental Psychology Fourth Edition, Philadelphia: Harcourt Brace College Publishers

reswell, J. (2003). Research Design: Qualitative, Quantitative, and Mixed Method 2-nd edition, California: SAGE Publication Erkip, F. (2002). The Shopping Mall as an Emergent Public Space in Turkey, Environment and Planning A 2003, vol.35, pp.10731093

Gehl, J (1986). Life Between Buildings: Using Public Space, New York: Van Nostrad Reinhold Company

Hurlock, E. (1996). Psikologi Perkembangan, Suatu Pendekatan Sepanjang Rentang Kehidupan, Jakarta : Erlangga Ibrahim, M. F \& Wee., N. C, (2002), The Importance of Entertainment in the Shopping Center Experience: Evidence from
Singapore, Journal of real Estate Portfolio Management, vol. 8, No. 3, 2002, pp. 239-254. 